\title{
Evaluation of Risk of Type 2 Diabetes Mellitus in Medical Students Using Indian Diabetes Risk Score (IDRS)
}

\author{
Tejashwini V.B.
}

Associate Professor, Department of Physiology, Basaveshwara Medical College \& Research hospital, Chitradurga

\begin{abstract}
Background: Diabetes as a non-communicable disease is significant public health problem all over the world. Type 2 Diabetes Mellitus (T2DM) is a disease that develops slowly and over time and only recently has it become evident that T2DM finds its presence even among the younger age groups. Therefore a cross sectional study has been conducted to evaluate and assess the risk for developing T2DM among undergraduate students using Indian Diabetes Risk Score(IDRS), a questionnaire that is simple, validated and has proven to be highly effective in previous studies.
\end{abstract}

Objectives: To evaluate the risk of developing diabetes among medical students using Indian Diabetes Risk score.

Method: The study included 100 MBBS students. Detailed history was taken which includes information regarding their age, family history of diabetes and exercise. Waist circumference was measured .Risk of diabetes was calculated using Indian Diabetes Risk Score.

Results: Risk of developing diabetes was high in $6 \%$, moderate in $87.3 \%$ and low in $9.7 \%$ of students.

Conclusion: Risk of diabetes was present in more than $50 \%$ of medical students as assessed by Indian Diabetes Risk Score.

Keywords: Type 2 Diabetes mellitus, IDRS, Obesity, Physical activity, Family history.

\section{Introduction}

India leads the world with the highest number of diabetic patients earning the distinction of being termed the "diabetes capital of the world". ${ }^{[1]}$ It is estimated that the number of diabetic subjects will rise to 69.9 million from 42 million by the year 2025 . We can expect diabetes to have a serious damaging impact on the longevity as well as the quality of life in India. The increasing modernization, sedentary lifestyle and unhealthy

\section{Corresponding Author:}

\section{Tejashwini V.B.}

Associate Professor, Department of Physiology, Basaveshwara Medical College, Chitradurga-577501, Karnataka

e-mail: teju23091987@gmail.com dietary habits in rural and urban India has taken its toll on the health of the general public, especially the youth. ${ }^{[2]}$ Diabetes mellitus(DM) can be split primarily into two types: Type I or Insulin dependent diabetes mellitus(IDDM) and Type 2 or Non- insulin dependent diabetes mellitus(NIDDM). Type $2 \mathrm{DM}(\mathrm{T} 2 \mathrm{DM})$ is a nonincapable of producing enough insulin, characterized by abnormal glucose homeostasis. Its pathogenesis appears to involve complex interactions between genetic predisposition and environmental factors. ${ }^{[3]}$ T2DM occurs when impaired insulin resistance is accompanied by the failure to produce ample amount of $\beta$-cell insulin. ${ }^{[4]}$

Evidences suggest that premature detection of diabetes by suitable screening method, especially in subjects with elevated risk for diabetes will help to intercept or delay the vascular complications and thus reduce the clinical, social and economic burden of the 
disease. Indian Diabetes Risk Score (IDRS) is a simple and effective screening tool to evaluate risk of diabetes in future. It involves four parameters namely age, parental family history of diabetes, $\mathrm{WC}$ and physical activity to calculate the score as shown in table 1 . A score of $>60$ denotes high risk, 30 - 50 moderate and $<30$ low risk. ${ }^{[1]}$ In the present study the risk of diabetes in medical students was evaluated using IDRS.

\section{Table 1: Indian Diabetes Risk Score}

\begin{tabular}{|c|c|}
\hline Particulars & Score \\
\hline \multicolumn{2}{|l|}{ Age (Years) } \\
\hline$<35$ (reference) & 0 \\
\hline $35-49$ & 20 \\
\hline$>50$ & 30 \\
\hline \multicolumn{2}{|l|}{ Abdominal obesity: } \\
\hline Waist <80 cm (female), <90 (male) (reference) & 0 \\
\hline Waist $>80-89 \mathrm{~cm}$ (female), $>90-99 \mathrm{~cm}$ (male) & 10 \\
\hline Waist $>90 \mathrm{~cm}$ (female), $>100 \mathrm{~cm}$ (male) & 20 \\
\hline \multicolumn{2}{|l|}{ Physical activity: } \\
\hline Exercise [regular] + strenuous work [reference] & 0 \\
\hline Exercise [regular] or strenuous work & 20 \\
\hline No exercise and sedentary work & 30 \\
\hline \multicolumn{2}{|l|}{ Family history } \\
\hline No family history [reference] & 0 \\
\hline Either parent & 10 \\
\hline Both parents & 20 \\
\hline Minimum score & 0 \\
\hline Maximum score & 100 \\
\hline
\end{tabular}

Objectives: To evaluate the risk of developing diabetes among medical students using Indian Diabetes Risk Score.

\section{Method}

The study included 100 MBBS students. Ethical Clearance was obtained from Institutional Ethical Committee and informed consent was taken. Any known case of type 2 DM, PCOD, thyroid disorder were excluded from the study. Detailed history was taken about age, family history of diabetes and exercise. Students performing moderate to vigorous physical activity for at least 20 minutes a day regularly or 150 minutes per week were grouped under positive exercising group. ${ }^{[5]}$ Measurement of the WC was taken directly on the body with light clothing midway between the lowest rib and the iliac crest and hip circumference at the level of the greater trochanters with legs close together, after a normal expiration using a non-stretchable measuring tape by average of three measurements nearest to 0.5 $\mathrm{cm}^{[6]}$ The individuals were classified as having high risk (score $>60$ ), moderate risk (score 30-50) and low risk (score $<30$ ) out of a total score of 100. ${ }^{[7],[1]}$

Statistics: Descriptive analysis was carried out to evaluate the risk of developing diabetes in them and presented categorically in percentage

\section{Results}

Mean age of the study group was $19.3+1.4$ years. Out of 100 students, 50 were females and 50 males. The distribution of WC is shown in table $2.30 .6 \%$ of the students had parental history of diabetes. $28.6 \%$ of them had history of one parent being diabetic and $2 \%$ had both parents diabetic. Only $15 \%$ of them were exercising regularly and rest $85 \%$ were non exercising. Risk of diabetes was calculated using Indian Diabetes Risk Score (IDRS) as shown in table 3.

Table 2: Distribution of WC among medical students:

\begin{tabular}{|l|l|c|c|c|c|}
\hline & & \multicolumn{2}{|c|}{ Females } & \multicolumn{2}{c|}{ Males } \\
\hline \multirow{2}{*}{ WC } & Cut off & $<80 \mathrm{~cm}$ & $>80 \mathrm{~cm}$ & $<90 \mathrm{~cm}$ & $>90 \mathrm{~cm}$ \\
\cline { 2 - 6 } & $\%$ of student & 60 & 40 & 65 & 35 \\
\hline
\end{tabular}

Table 3: Risk of developing diabetes mellitus in medical students

\begin{tabular}{|l|c|c|c|}
\hline IDRS & High (>60) & Moderate (30-50) & Low $(<\mathbf{3 0 )}$ \\
\hline & $6 \%$ & $87 \%$ & $7 \%$ \\
\hline
\end{tabular}

\section{Discussion}

In this cross sectional study, 100 MBBS students were enrolled. Indian diabetes risk score was used to predict risk of developing diabetes in them. As all the students were less than 35 years of age, all obtained a score of zero for age. Therefore the score was calculated using waist circumference, parental family history and exercise. Based on Asian standards ${ }^{[7]}$, central obesity as predicted by WC was prevalent in $40 \%$ of females and $35 \%$ of males. Central obesity specially is shown to be an important risk factor for cardio metabolic diseases. Unlike subcutaneous fat, visceral fat is drained by the portal venous system and has a direct connection with the liver, resulting in an influx of free fatty acid availability 
in the liver. In visceral fat, mobilization of free fatty acids is faster because of higher lipolytic activity in visceral adipocytes, resulting in higher free fatty acids in the systemic circulation where it forms plaque on the artery walls, resulting in high blood pressure and cardiovascular disease. Additionally, an influx of free fatty acid availability in the liver decreases hepatic insulin extraction, resulting in systemichyperinsulinemia, and inhibits the suppression of glucose production by insulin. ${ }^{[8]}$ Parental history of diabetes was present in around $30 \%$ of the students. And $85 \%$ of the students were not exercising regularly neither were they performing any strenuous work. The sedentary lifestyle is independent risk factor of diabetes. After computing for IDRS scores it was found that $6 \%$ of the subjects were already in the high risk group. Around $87 \%$ were in moderate risk group. If steps are not taken to control their obesity, they may land up in high risk group after age of 35 years. Our results are consistent with a similar study done in Pune which showed $4 \%$ in high risk group and $76 \%$ in moderate risk. ${ }^{[9]}$ Another study done in Mangalore revealed $1 / 3$ rd of students at high to moderate risk. ${ }^{[10]}$

\section{Conclusion}

Abdominal obesity was present in more than $50 \%$ of the medicos. Around one third of the students had positive family history of diabetes. Also a high percentage $(85 \%)$ of them was sedentary. The current data shows an increased risk of diabetes in most of them. Family history is a non modifiable factor. Therefore immediate steps should be taken to reduce the obesity by encouraging these students to increase physical activity and diet control.

Acknowledgements: We would like to thank all the first year MBBS students who participated in the study.

\section{Source of Funding: Self}

\section{Conflicts of Interest: Nil}

Ethical Clearance: Taken from college Ethical committee.

\section{References}

1. Mohan V, Sandeep S, Deepa R, Shah B, Varghese C. Epidemiology of type 2 diabetes: Indian scenario. Indian J Med Res 2007;125:217-30.

2. Sumedh S Hoskote, Shashank R Joshi,Are Indians Destined to be Diabetic? J Assoc Physicians India,56,2008,225-226.

3. Gupta V, Khadgawat R, Saraswathy KN, Sachdev MP and Kalla AK, Emergence of TCF7L2 as a Most Promising Gene in Predisposition of Diabetes Type II,Int J Hum Genet, 8(1-2),2008, 199-215.

4. Permutt MA, Wasson J, Cox N, Genetic Epidemiology of Diabetes, Jornal of clinical Investigation, 115(6),2005,1431-1439

5. Sigal RJ, Kenny GP, Wasserman DH, Sceppa CC, White RD. Physical Activity/Exercise and Type 2 Diabetes. Diabetes Care 2006; 29:1433-38.

6. Rowett Institute of Nutrition and Health [homepage on the Internet]. Aberdeen: University of Aberdeen; [cited 2012 Aug 12]. Body composition.[About 6 screens]. Available from: http:/www.rowett.ac.uk/ edu_web/sec_pup/body_comp.pdf.

7. Mohan V, Deepa R, Deepa M, Somannavar S,Datta M.A Simplified Indian Diabetes Risk score for screening For undiagnosed Diabetic Subjects

a. J Assoc Physicians India 2005;53:759-63.

8. Menke A, Muntner P, Wildman RP, Reynolds K, He J. Measures of Adiposity and Cardiovascular Disease Risk Factors. Obesity 2007;15:785-95.

9. Ashok P, Kharche JS, Joshi AR. Evaluation of risk for type 2 diabetes mellitus in medical students using Indian Diabetes Risk Score - step I. Indian

10. Vardhan A, Prabha A, Shashidhar K., Shankar N., Gupta S, Tripathy A. Value of Indian Diabetes Risk Score among Medical Students and Its Correlation with Fasting Plasma Glucose, Blood Pressure and Lipid Profile. J Clin Diagn Res 2012;6:1528-30. 